\title{
Research groups to leave Hunterian Institute
}

London. Basic research at the Royal College of Surgeons of England is coming to the end during the next several months as its research departments are either moved out or closed down. Although the college says that it will continue to fund the groups, the affected departments are trading a secure home for the unstable world of the London teaching hospitals.

The changes come as a result of an internal review of the workings of the Hunterian Institute, that part of the college responsible for research and education. The college's president, Norman Browse, declined to comment on the changes, but officials are said to feel that the college is no longer the best place to carry out basic research and that the departments would be better off closer to their clinical counterparts.

Outside observers say that space has become a problem, with laboratories being swallowed up by administrative offices. Some say that a lack of space has prevented the research groups from attaining or maintaining the critical mass they need to be really successful. What will remain after the changes, apart from administrative offices, is an expanded anatomy department devoted to applied surgical research and a greater emphasis on teaching.

The institute was formed in 1986 by the merger of the Institute of Basic Medical Science, co-administered by the college and the University of London, and the college's own research departments in anaesthetics, ophthalmology and the dental sciences. In 1990-91 the Hunterian Institute spent $£ 2.3$ million (US\$4.5 million) on research, drawn from both the college and external project grants.

Most of the changes are taking place within the departments from the old Institute of Basic Medical Science. Biophysics and pharmacology will both be moving, while a decision about pathology is awaited. The biochemistry department will be closed when its head, Neville Crawford, retires. The master of the Hunterian Institute, Sir Stanley Peart, will also be retiring later this year, and the college has yet to decide whether to appoint a successor.

Although the Hunterian itself is only six years old, the tradition of research at the college dates from the 1950 s and includes such prominent figures as Nobel laureate $\mathrm{Sir}$ John Vane. The Imperial Cancer Research Fund (ICRF) laboratories at Lincoln's Inn Fields began as part of the college before the need for more space forced it to move next door. Links between the two are still strong, with some sharing of library and scientific resources, and staff at the ICRF are unhappy with the move.

Meanwhile, the groups' new landlords are not overwhelmingly inviting. Medical researchers in London are awaiting next month's publication of the Tomlinson re- port, which is expected to suggest a strategic rearrangement of the London teaching hospitals, some closures and an inevitable loss of research teams. Some claim that the uncertainty alone has damaged research work (see Nature 357, 617; 1992).

Although staff at the institute are unhappy about the changes, they are reluctant to speak publicly. They say that they expect the college to continue its support and that their research groups are "fit and well". However, they are more outspoken on the subject of the general malaise in medical research. "Wherever you look, all you can see is an 'if'," says Nina Wedderburn, academic dean of the institute and a member of its pathology department.

lan Mundell

\section{He's not heavy, he's my fossil}

\section{IMAGE UNAVAILABLE FOR COPYRIGHT REASONS}

A Chinook helicopter lifts a rock and plaster bundle containing most of a stegosaurus, a manoeuvre required to extract the rare specimen from the Colorado site where it was found in June. The nearly complete stegosaurus skeleton includes only the second intact skull to have been found, according to Ken Carpenter, a Denver Museum of Natural History palaeontologist who led the dig.

Because the skeleton is so well-preserved, researchers have been able to confirm that the stegosaurus's characteristic back plates are arranged in an alternating pattern (some theories had them in matched pairs) and that the animal had even more body armour than had been previously thought, including a disk-shaped plate near its hip and a web of ossicles - small coin-sized bony plates - in its throat region. Carpenter notes that the new find's back plates are much larger than a previous specimen (presumably of the same species) found only 300 yards away in 1931, which may suggest that plate size is an indication of gender and that the specimen is a male. 